\title{
Use of gamification as collaborative learning resources
}

\author{
Nicanor Concepción García
}

\begin{abstract}
There is no doubt that students in contact with Information and Communication Technologies (ICT) benefit in various ways and advance in this new vision of the user of training. Gamification is a learning tool that is being used more frequently, and acquiring great relevance in the field of education, with the implementation and use of this support tool as a collaborative resource in a vital campus, it was proven that it is beneficial to improve the performance and quality of education in students who take the subject of Arithmetic and Geometry. At the ISOFODOSU.

The purpose of this article is to present the results obtained from the intervention with students enrolled in the subject Arithmetic and Geometry in the academic periods September - December 2019, January April 2020, on gamification in a virtual learning environment as a collaborative resource in combination with mobile devices. The objective set by the researcher is to check whether the use of this collaborative tool combined with mobile devices can improve academic performance, and increase the grades of students enrolled in the subject at the Salome Ureña Higher Institute of Teacher Training.
\end{abstract}

Keywords: Gamification, collaborative learning, educational resources, technological tools. Videogame

\subsection{Introduction}

This research study seeks to solve a problem that focuses on the lack of a teaching-learning methodology that adjusts to the needs of students enrolled in the education career of the Higher Institute of Teacher Training Salome Ureña, the use of The traditional methodology to teach the classes and the lack of appropriate study materials, has caused that these students do not obtain the necessary development and skills, in the subject arithmetic and Geometry, these results are reflected in the statistics of the revised academic records In the academic periods of 2017, 2018 and 2019, the high rate of students with low grades. It is a concern for academic authorities.

With the implementation of this collaborative tool in combination with mobile devices in an educational environment in the academic period September-December 2019 and January-April 2020 it is a reality, so that students can access the available technological resources, virtual learning campus, databases, social networks. With this implementation it is evidenced that students enrolled in the subject in the face-to-face study modality of the education career have benefited because they increased academic performance and improved their grades.

\subsection{Research Context}

Reviewing the academic records of the Arithmetic and Geometry subject at the Feliz Evaristo Mejía and Juna Vicente Moscoso university campuses of two (2) sections of classes that comprise the academic periods 2017, 2018 and 2019. The results achieved reflect that the students have difficulties with the subject, due to the low grades obtained during the academic periods examined. Most of these students have insufficient grades to pass the course. It has been observed in the records that approximately $32 \%$ of the students enrolled in this subject have a learning problem. This problem is causing future teachers to graduate with disabilities to be able to exercise their profession as a trainer.

The review has been able to identify the presence of a problem faced by students in the education career program.

To improve these results, a study modality different from the traditional one was implemented in the academic periods September - December 2019, January - April 2020, gamification in a virtual learning 
environment using Moodle as a technological platform to accompany the students in the teaching process learning, being their responsibility and ensuring that they achieve the necessary skills in the subject.

\subsection{Theoretical fundament}

This research work corresponds to a case study on Information and Communication Technologies in an Educational Setting at the university level, in the Research line "E-learning, Virtual Platforms in a Learning Environment.

This section presents the main learning theories that are related to the use of information and communication technology. The most relevant resources that can be used to support education, gamification, mobile devices, electronic devices that are used for interconnection to the available technological platform. the tools that are related to the educational environment, such as mobile devices, tablets, desktop computers, laptops. According to what this car says "Digital literacy, as an educational action, acquires a crucial role in the appropriate use of technologies within higher education institutions" (Gamboa, 2016, p.2), the virtual learning environments, describing the characteristics of a gamification environment using the Moodle platform in a virtual learning field, as a collaborative tool, which can be used as a resource to support the teaching and learning process, in the training of students. new teachers ... "teachers feel that Gamification is contributing positively to the learning process of their students" (Alabbasi, 2018, p. 39). Gamification is being used as an alternative to improve education so that students can have access to the virtual campus from anywhere using mobile devices.

The changes that mobile devices have undergone in Latin America place it as the most developed means of communication in society, this is located in the context of learning based on Mobile Learning or Mobile Learning. This technology is positioned as one of the tools that has had the greatest development in the educational field due to the easy and quick access to information, and has transformed it into one of the learning methods most used by students. This tool is basic for creating learning micro-contents, which facilitates the visualization of the contents in a virtual learning environment. There is no doubt that students are in contact with technology and benefit in many ways, which allows them to advance in their development as user in training. This requires that the selection, use and organization of the information be of quality so that the student gradually develops as a mature citizen of the information society. (Salinas, 2004)

\subsection{Moodle Mobile.}

Moodle Mobile is a technological platform that strives to offer an unforgettable experience for students, and that they can take advantage of this tool as a quality support, and thus can improve the learning process, this tool provides the teacher with facilities to manage tasks assigned to students, this system is uniquely integrated, due to the security it offers to universities because it guarantees the information, different learning environments can be created according to the needs that the teacher may have, it also has a module for Add mobile devices through the Moodle Mobile APP, this allows you to view all the course contents from other devices that have an internet connection, this new method of education facilitates the consultation of all the contents, the practices for teachers and students, has the facility to connect from anywhere and at any time ment to the platform, in this platform the administrator has the responsibility of enabling access to smartphones.

Mobile devices and tablets are the electronic means of communication most used by students (Sanjaya, Eva, Soekesi, Posmaria, \& Sitohang, 2015, p.3) these are the most common means among young people in the classroom, these are more easily incorporated into the educational context of Mobile Learning. Students use this tool because of the ease it provides to connect to the Moodle platform and educational video games, when using these Mobile Learning devices or mobile learning, according to this author (Cient, Profesional, \& Pedagog, 2017, p.12) "With the use of ICT, access to the resources provided from the classroom is guaranteed", with the incorporation of mobile devices as a necessary learning tool to facilitate access from anywhere to the platform to review educational content. This model of education has become a trend for students. 
The evolution of mobile devices in recent years has contributed to the development of multiple technologies such as: web 2.0 (blogs, wikis, social networks, social bookmarks), open digital content, augmented reality, portable video game consoles, devices multifunctional mobiles, STEAM computing, among other technological advances. The use of these tools has been fostered in all areas, including education, these advances have achieved that not only science and mathematics benefit but also contributing to the personal construction of students (Olabe, 201 7)

Mobile or mobile learning proposes a new pedagogical model that aims to exploit all the didactic potential of these devices and promote their use as an effective tool to facilitate teaching and learning in the educational context.

On the other hand, he affirms (Castaño, 2009) that micro-contents are produced, managed, put into circulation, enriched with semantic metadata, processed, remixed and used and / or consumed, it is a published information of a short, whose length and size is a function of sticking to a single main and relevant topic, and due to the physical and technical limitations of the software and hardware that we use to manage digital content.

The pedagogical use of this type of digital content has educational potential to be transmitted through mobile devices such as: smart phones or Smartphone, tablets, personal digital assistants (or its acronym in English PDA), multimedia playback consoles, games and Gamification etc. .). Referring to educational microcontent, (Marcia Izabel Fugisawa Souza, 2011) points out:

The micro-content is studied from the perspective of an object or element of learning with mobility. It is admitted that such a conception of microcontent favors the construction of new knowledge and the emergence of new interrelationships between concepts, with the possibility of broadening the range of students' understanding of the subject dealt with by the teacher. (p.1203).

(MARISCAL, 2010) indicate that mobile telephony has become the ICT with the highest penetration in the world. At the end of 2009 , there were more than 4.6 billion active mobile phones, a base more than four times larger than that of fixed telephony. In Latin America, as of March 2015, the number exceeded 550 million, equivalent to a penetration of more than $91 \%$ [...]. Mobile technology has reached segments of the population that no other ICT has reached (p.2,3).

Gamification used as a learning tool in combination with mobile devices has contributed to improving the academic performance of the students who participated in the experiment, in the intervention, September December 2019 it was found that $74.59 \%$ of the students improved their academic performance In the second intervention of the experiment, in the academic period January, April 2021, the results obtained average $75.25 \%$.

\subsection{Methodology}

To carry out the intervention, two groups were created with the students enrolled in the first semester of the education career of the subject Arithmetic and geometry, the first group was selected as experimental, and the instruments that consist of a test, pretest, were applied to it. At the beginning of the semester, at the end of the intervention the post-test test was applied, the first test was carried out to measure the degree of knowledge at the beginning of the semester, then the experiment was carried out. This was carried out from the beginning of the semester to the end, for the experience gamification was implemented as a collaborative tool in a virtual learning environment, this methodology was used in combination with mobile devices, in the academic period September - December 2019, January - April 2020. At the end of the intervention, the second test was applied. For the second group of the experiment, the pretest test was applied at the beginning of the semester and the second post-test test at the end of the semester. This group was selected as a control group and the class continued with the traditional method until the second month, after having concluded the second part of the semester, the intervention was carried out with the students applying the treatment until the end of the intervention with the students, consists of an experiment implementing gamification as a collaborative tool using Moodle 3.8 as collaborative resources in a virtual learning environment in combination with mobile devices in the academic period September - December 2019, January - April 2020. 
For this intervention, the researcher had the collaboration of the teacher of the Arithmetic and Geometry subject to follow up with the students and thus comply with the research requirements, so that the results were not altered. The intervention was carried out with a population of students from the educational program that teaches enrolled in the subject Arithmetic and Geometry.

The experimental group consisted of 77 students, divided into two academic periods; The first part of the experiment was developed from September to December 2019, consisting of an enrollment of 42 students, and the second experiment was carried out in the academic period corresponding to January - April 2020, consisting of an enrollment of 35 students.

The control group consisted of an enrollment of 80 students divided into two academic periods, the first intervention was carried out in the second month of the semester in the academic period September December 2019, this group consisted of 43 students and the second intervention was carried out in the academic period January - April 2020, made up of 37 students, enrolled in the Arithmetic and Geometry subject of the first semester of the education career.

In this intervention, a mixed methodological deepening was implemented, that is, a combination of a quantitative approach and a qualitative approach was used, according to what this author says: "The quantitative approach uses data collection to test hypotheses with based on numerical measurement and statistical analysis, in order to establish behavioral guidelines and test theories "(Hernández, Fernández, \& Baptista, 2014, p. 4); Usually the qualitative approach "uses data collection and analysis to refine research questions or reveal new questions in the interpretation process" (Hernández, Fernández, \& Baptista, 2014, p. 7).

The experimental design is characterized by the evaluation of the effect that arise from one or more interventions, to comply with the objectives and hypotheses raised and thus provide an answer to the research questions. This design has the characteristic of intentional manipulation of the variable so that its possible results can then be analyzed (Hernández, Fernández, \& Baptista, 2014).

Table 1 - Experimental design with two groups

\begin{tabular}{|l|l|l|}
\hline \multicolumn{3}{|c|}{ Two-group experimental designs 2019 AND 2020} \\
\hline X & 01 experimental & Pretest, Post Test, Satisfaction Survey, Focus Groups \\
\hline-- & 02 control & Pretest, Post Test. \\
\hline
\end{tabular}

\subsection{Results.}

In this section, the results obtained from the instruments that were used to collect the data are detailed, such as: the pre-test pass questionnaire and the post-test that was applied to the experimental and control groups. In addition, the results obtained from the academic attitude satisfaction survey are presented. These tests were applied in order to measure academic performance by using Gamification as a study methodology different from the traditional one in combination with the use of mobile devices, to achieve improved academic performance in the teaching and learning process of the subject. of arithmetic and geometry, this learning methodology was designed from the implementation of a quasi-experimental case study.

a. The questionnaire was applied to check the academic performance at the beginning of the subject of arithmetic and geometry to the students of the first semester of the Félix Evaristo university campus (pre-test)

b. The questionnaire was applied to verify the academic performance at the beginning of the subject of arithmetic and geometry to the students of the first semester of the Juan Vicente Moscosos university campus (pre-test)

c. The questionnaire was applied to check the academic performance at the end of the subject of arithmetic and geometry to the students of the Félix Evaristo Mejía University Campus in Santo Domingo (post-test) 
d. Qualifications obtained by the students of the Juan Vicente Moscos, San Pedro de Macorís and Félix Evaristo Mejía University Campus of the city of Santo Domingo in the tests carried out at the beginning of the intervention.

e. Qualifications obtained by the students of the Juan Vicente Moscoso University Campus in San Pedro de Macorís at the end of the course using the new teaching methodology proposed at the end of the semester.

f. Qualifications obtained by the students of the Félix Evaristo Mejía University School in Santo Domingo at the end of the course, using the Gamification methodology in a virtual learning environment, designed from a synchronous implementation and structure.

g. The satisfaction survey was applied at the end to assess the level of confidence regarding the use of mobile devices, used as learning resources in combination with the new Gamification methodology

\subsection{Gamification Methodology}

For the training of quality teachers required by the educational system of the Dominican Republic in the area of education is under the responsibility of the Ministry of Higher Education Science and Technology. (MESCYT). Most of the aspiring teachers of schools and colleges are obtained mainly by the Higher Institute of Teacher Training Salome Ureña. They are distributed in all the premises of the ISFODOSU. This institution is the patrimony of the Dominican state, the university campuses under study are located in the city of Santo Domingo and in the city of San Pedro de Macorís respectively. These university campuses exclusively dictate the face-to-face modality for the teaching of their subjects, with a total of approximately 1,100 students enrolled in each semester of the different teaching courses they offer.

Teachers are opposed to structuring the teaching of arithmetic and geometry subjects in a virtual way; However, for this research work, a virtual learning environment was implemented using Gamification as a collaborative tool in combination with mobile devices as learning resources, for the research a quasiexperimental case study was implemented, for the selected subject, to teach in virtual mode under the Gamification methodology and thus achieve the researcher's objective. A training on the use of this methodology was carried out to the selected professors to teach the subject Arithmetic and Geometry in the virtual platform using Moodle 3.8. The first teachers who received training on how to use this methodology in Moodle correspond to teachers from the Félix Evaristo Mejía campus. For the reason that the group of students in this campus was selected as an experimental group, they were provided with a computer lab, as long as these students did not have the facility to use a computer or some electronic means to access classes virtual from their homes.

The second group of teachers who received the training correspond to the Juan Vicente Moscoso campus, these teachers were trained so that they can use the Moodle platform, and thus accompany the students of the control group at the end of the semester.

To apply the pre-test and post-test instruments, an instrument was built, which consists of a test of

The second group of teachers who received the training correspond to the Juan Vicente Moscoso university campus, these teachers were trained so that they can use the Moodle platform, and thus accompany the students of the control group at the end of the semester.

To apply the pre-test and post-test instruments, an instrument was built, which consists of an exam-type academic attitude test with practical exercise, closed questions where students have to give the correct answer, for each of the questions, For this instrument, a scale that goes from one (1) to two (2) points, according to the next scale:

\begin{tabular}{|l|l|}
\hline \multicolumn{2}{|l|}{ Pre-test and post-test assessment scale } \\
\hline 1 & Correct \\
\hline 2 & Incorrect \\
\hline
\end{tabular}

Table 2 - Pre-test and post-test rating scale.

\subsection{Pretest Test Results}

This test was applied in the semester September-December 2019, at the Félix Evaristo Mejía and Juan Vicente Moscoso campuses, to a total of 85 students enrolled in the first semester, in the subject of arithmetic and geometry of the education career. These were divided into two groups: 43 students belong to 
the Juan Vicente Moscoso University Campus, and 42 students to the Félix Evaristo Mejía University Campus, the main objective of this test is to measure the level of knowledge of the students in the subjects Arithmetic and Geometry before start the intervention of the Gamification methodology in a virtual learning environment. Likewise, for the four-month period of January - April 2020, the experiment was carried out on a total of 72 students from both university campuses, stratified into: 37 students from the Juan Vicente Moscoso Campus and 35 students from the Félix Evaristo Mejía Campus.

Table 3- This table represents the two groups of selected students who participated in the experiment.

\begin{tabular}{|l|c|c|}
\hline University Campus & Year & $\begin{array}{l}\text { Total of students enrolled in the semester } \\
\text { September-December }\end{array}$ \\
\hline $\begin{array}{l}\text { Juan Vicente } \\
\text { Moscoso }\end{array}$ & 2019 & 43 \\
\hline Félix Evaristo Mejía & 2019 & 42 \\
\hline Total & & 85 \\
\hline
\end{tabular}

Tabla 4- que representa los estudiantes, del grupo experimental y de control que participaron en el experimento.

\begin{tabular}{|l|l|c|}
\hline University Campus & Year & $\begin{array}{l}\text { Total of students enrolled in the } \\
\text { January-April semester }\end{array}$ \\
\hline Juan Vicente Moscoso & 2020 & 37 \\
\hline Félix Evaristo Mejía & 2020 & 35 \\
\hline Total & & 72 \\
\hline
\end{tabular}

Table 39 - 5th. Arithmetic Operation Questionnaire Pre-test Juan Vicente Moscoso and Félix Evaristo Mejía university campuses Semesters September - December 2019 and January - April 2020

\begin{tabular}{|c|c|c|c|c|c|c|c|}
\hline & & $\begin{array}{l}\text { Septem } \\
\text { ber } \\
\text { Decem } \\
\text { ber } \\
2019\end{array}$ & $\begin{array}{l}\text { Percent } \\
\text { age } \\
\text { valid } \\
2019\end{array}$ & $\begin{array}{l}\text { Janu } \\
\text { ary } \\
\text { April } \\
2020\end{array}$ & $\begin{array}{l}\text { Percentag } \\
\text { e } \\
\text { valid } \\
2020\end{array}$ & $\begin{array}{l}\text { Tota } \\
1\end{array}$ & $\begin{array}{l}\text { Percentag } \\
\mathrm{e} \\
\text { valid } \\
\text { Total }\end{array}$ \\
\hline \multirow{2}{*}{$\begin{array}{l}\text { Juan } \\
\text { Vicente } \\
\text { Moscoso }\end{array}$} & $\begin{array}{l}\text { Corre } \\
\text { ct }\end{array}$ & 11 & 25.58 & 10 & 27.03 & 21 & 26.25 \\
\hline & $\begin{array}{l}\text { Incorr } \\
\text { ect }\end{array}$ & 32 & 74.42 & 27 & 72.97 & 59 & 73.75 \\
\hline \multicolumn{2}{|c|}{$\begin{array}{ll}\text { Total, Juan } \\
\text { Vicente Moscoso } \\
\end{array}$} & 43 & 100.00 & 37 & 100.00 & 80 & 100.00 \\
\hline \multirow{2}{*}{$\begin{array}{l}\text { Félix } \\
\text { Evaristo } \\
\text { Mejía }\end{array}$} & $\begin{array}{l}\text { Corre } \\
\text { ct }\end{array}$ & 9 & 21.43 & 7 & 20.00 & 16 & 20.78 \\
\hline & $\begin{array}{l}\text { Incorr } \\
\text { ect }\end{array}$ & 33 & 78.57 & 28 & 80.00 & 61 & 79.22 \\
\hline \multicolumn{2}{|c|}{$\begin{array}{l}\text { Total, Félix } \\
\text { Evaristo Mejía }\end{array}$} & 42 & 100.00 & 35 & 100.00 & 77 & 100.00 \\
\hline
\end{tabular}

Also, for the arithmetic operation: 0.258 x 3.4, the students of the Juan Vicente Moscoso university campus in the semester of September - December 2019, answered correctly in 25.58\%, and the students of the Félix Evaristo Mejía university campus in the semester September - December 2019 answered correctly for $23.81 \%$.

For the semester of January - April 2020, the students of the Juan Vicente Moscoso university campus answered correctly in $18.92 \%$, being the students of the Félix Evaristo Mejía university campus, those who 
had the lowest percentage of correct response for a $14.29 \%$. Table 40 presents the results of the correct and incorrect answers for both university campuses.

Table 40 - 6th. Arithmetic Operation Questionnaire Pre-test

Juan Vicente Moscoso and Félix Evaristo Mejía university campuses

Semesters September - December 2019 and January - April 2020

\begin{tabular}{|c|c|c|c|c|c|c|c|}
\hline & & $\begin{array}{l}\text { Septem } \\
\text { ber } \\
\text { Decem } \\
\text { ber } \\
2019\end{array}$ & $\begin{array}{l}\text { Percent } \\
\text { age } \\
\text { valid } \\
2019\end{array}$ & $\begin{array}{l}\text { Janu } \\
\text { ary } \\
\text { Apri } \\
1202 \\
0\end{array}$ & $\begin{array}{l}\text { Perce } \\
\text { ntage } \\
\text { valid } \\
2020\end{array}$ & $\begin{array}{l}\text { Tot } \\
\text { al }\end{array}$ & $\begin{array}{l}\text { Percentag } \\
\mathrm{e} \\
\text { valid } \\
\text { Total }\end{array}$ \\
\hline \multirow{2}{*}{$\begin{array}{l}\text { Juan } \\
\text { Vicente } \\
\text { Moscoso }\end{array}$} & Correct & 11 & 25.58 & 7 & 18.92 & 18 & 22.50 \\
\hline & $\begin{array}{l}\text { Incorre } \\
\text { ct }\end{array}$ & 32 & 74.42 & 30 & 81.08 & 62 & 77.50 \\
\hline \multicolumn{2}{|c|}{$\begin{array}{l}\text { Total, Juan Vicente } \\
\text { Moscoso }\end{array}$} & 43 & 100.00 & 37 & $\begin{array}{l}100.0 \\
0\end{array}$ & 80 & 100.00 \\
\hline \multirow{2}{*}{$\begin{array}{l}\text { Félix } \\
\text { Evaristo } \\
\text { Mejía } \\
\end{array}$} & Correct & 10 & 23.81 & 5 & 14.29 & 15 & 19.48 \\
\hline & $\begin{array}{l}\text { Incorre } \\
\mathrm{ct}\end{array}$ & 32 & 76.19 & 30 & 85.71 & 62 & 80.52 \\
\hline \multicolumn{2}{|c|}{$\begin{array}{l}\text { Total, Félix Evaristo } \\
\text { Mejía }\end{array}$} & 42 & 100.00 & 35 & $\begin{array}{l}100.0 \\
0\end{array}$ & 77 & 100.00 \\
\hline
\end{tabular}

Graph 5 - Results of the Juan Vicente Moscoso University Campus Questions from 9 to 15

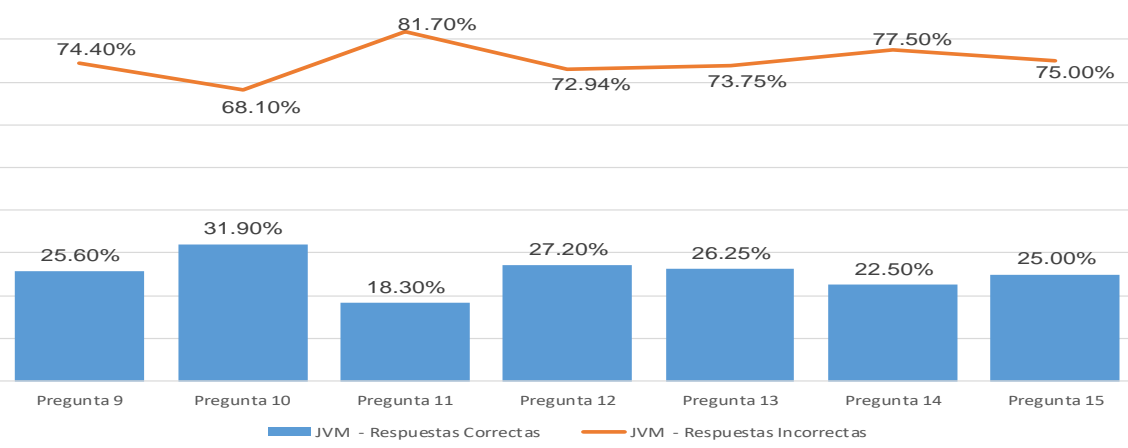

Graph 6 - Results of the Juan Vicente Moscoso University Campus Questions from 9 to 15

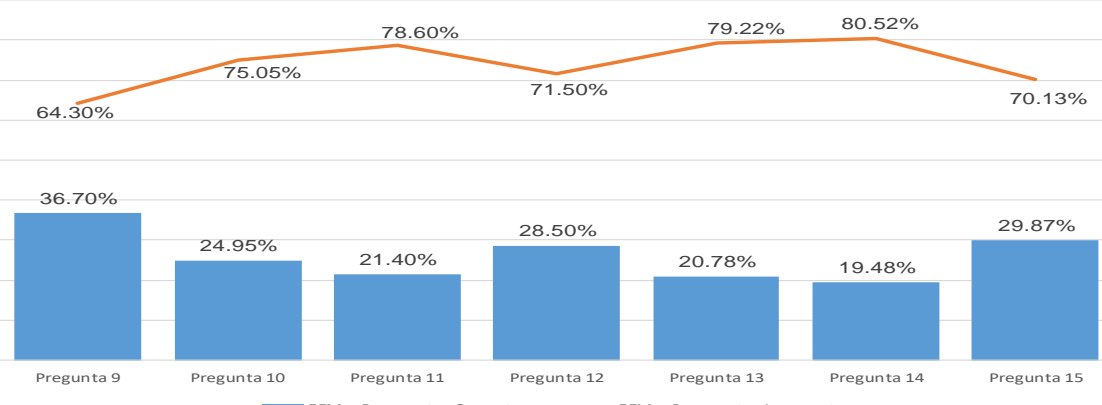

\subsection{Post-test tests}

This instrument was applied at the end of the semester once the intervention with the selected students had ended, which corresponds to the Félix Evaristo Mejía University Campus, this group was chosen as 
experimental, this intervention was carried out in the semesters between September - December 2019 and January - April 2020, with a total of 42 and 35.

Table 5 - representing the students of the experimental group who participated in the experiment.

\begin{tabular}{|l|l|l|}
\hline Campus & Year & Total, de estudiantes Matriculado \\
\hline \multirow{3}{*}{ Félix Evaristo Mejía } & 2019 & 42 \\
\cline { 2 - 3 } & 2020 & 35 \\
\hline Total & & 77 \\
\hline
\end{tabular}

Table 6 - representing the students of the control group who participated in the experiment.

\begin{tabular}{|l|l|l|}
\hline Campus & Year & Total of students Enrolled \\
\hline \multirow{2}{*}{ Juan Vicente Moscoso } & 2019 & 43 \\
\cline { 2 - 3 } & 2020 & 37 \\
\hline Total & & 80 \\
\hline
\end{tabular}

In the graphs of the post-test, it shows the results of the evaluations of these last arithmetic operations that have been presented in tables 3 and 4, both of the correct and incorrect answers for the semesters of September - December 2019 and January -April 2020, as well as the control and experimental university campuses. It is about visualizing in a general way, the questions from 9 to 15 of this post-test that were presented previously, where with these results an idea of the skills obtained by the students in the methodology of Gamification of the Felix university campus can be offered Evaristo Mejía and his comparison with the combination of the traditional and virtual method that was staged on the Juan Vicente Moscoso campus. Regarding the result of the arithmetic operations in the post-test, the Félix Evaristo Mejía university campus in both four-month periods of the experiment obtained a percentage above the average of $81.70 \%$ of correct answers, unlike the university campus Juan Vicente Moscoso. Above 30 percentage points is the difference that divides both methods presented, which indicates that the use of the Gamification methodology in combination with mobile devices, and using Moodle as a support tool favors academic performance, and increases results. of the students

The following graph (11) shows the results of questions 1 to 8 considering only the semester September December 2019 in both university campuses. In this you can see a constant assessment of correct answers versus the incorrect answers presented, which suggests that students under this method of using the Gamification methodology in a virtual learning environment can achieve common objectives and as they are updated pdf files, multimedia files can teachers get students excited in their studies. So graph 12 that is presented later, shows considerable growth in the January - April 2020 semester, where new file formats, better multimedia and more practices were introduced where the student can expose more their critical thoughts and debate them with others.

\section{Graph 11 - Post-Test University Campus Weighted Results}

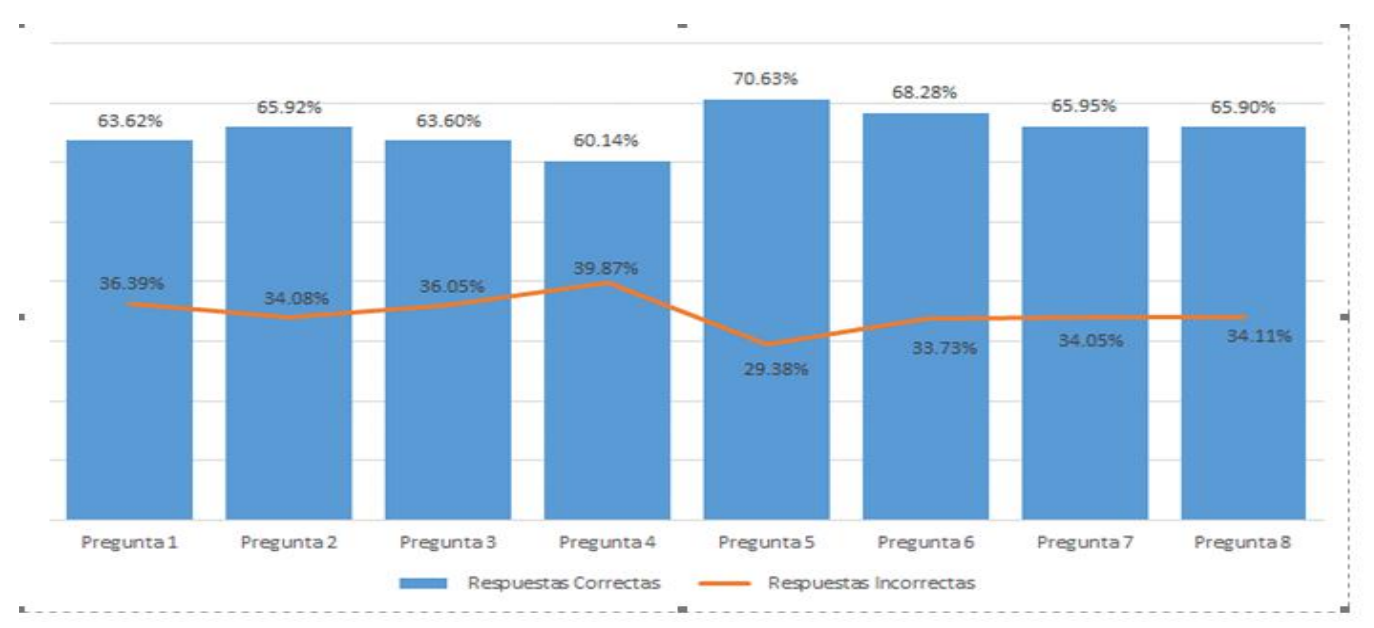


In graph 12, the results of the questions from 1 to 8 are presented, considering the four-month period January - April 2020, in both university campuses. As mentioned before, that the implementation of the methodology in a virtual learning environment is constantly growing, as long as the formats are kept updated, as happened in this four-month period and the results were significant in relation to the previous four-month period.

Graph 12 - Weighted Results for Post-Test University Campuses Questions 1 to 8 Semester January - April 2020.

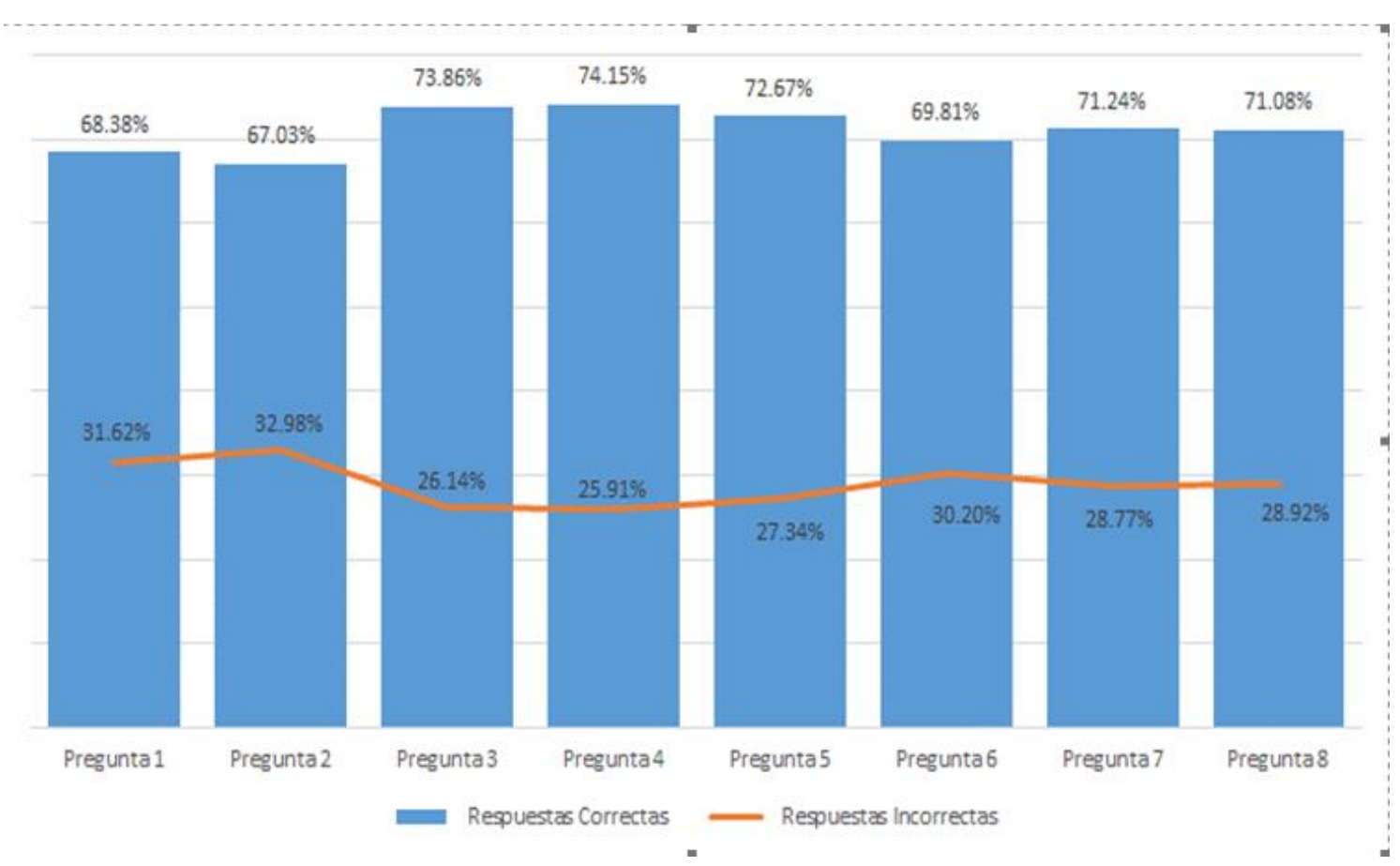

From a pragmatic point of view, these graphs show a level of knowledge of the students below expectations, even though at this point, the students had not received their classes in the subject of arithmetic and geometry. These significantly lower results in all the semesters obtained in this intervention, when applying the instrument of the pre-test academic attitude test, the reality of our times is evidenced, of how students prepare in the study of a certain subject before their culmination and their aspiration to receive a final grade in order to complete a certain subject, but they do not have the awareness of obtaining optimal results in a subject that subsequently allows the student to enter the career of their choice. However, the results obtained in the first pre-test of the intervention of the experiment show that students graduate from higher education with poor solidity of knowledge because the skills to interpret, analyze, explain and compare results have not been developed at the height of the needs it deserves.

\section{4.- Conclusions}

With the data obtained from the instruments applied in the pre-test and post-test tests, it was evidenced that students have a relationship between technology and the visualization-oriented teaching model to transmit knowledge whenever the relationship exists. In this research, motivation towards the use of ICT tools is promoted.

In the instruments presented in this experiment, students aged between 17 to 19 years old, 20 to 22 years old and 23 to 25 years old are seen as even though their knowledge in Arithmetic and Geometry was below expectations and Their interest in learning was more to finish their studies in the subject, rather than knowing and ensuring their professional growth, they received virtual teaching using the Gamification methodology in combination with mobile devices. With the use of this learning tool, they significantly increased their level of knowledge, their interest in the subject was better valued and they strengthened a bond of emotion that allowed them to achieve throughout this experiment a weighted average of $74.59 \%$ in correct answers using the Gamification methodology, when traditionally this percentage was $51.85 \%$. If this percentage presented by the semesters of this experiment is divided, in the semester of September December 2019, the students aged 17 to 19 from both campuses of the experiment, were those who in their 
initial test (pre-test), received the lowest grade for a $28.05 \%$ of correct answers, however, upon finishing their studies of arithmetic and geometry in the semester, the correct answers increased by $70.35 \%$. Likewise, for the semester of January - April 2020, these students aged 17 to 19, presented a score of $25.30 \%$ of correct answers in their pre-test test and $73.45 \%$ of correct answers in the post-test tests, when traditionally, this percentage was close to only $52.00 \%$.

For students aged 20 to 22 years, the percentage of correct answers in the initial test (pre-test) was $29.50 \%$ in the semester of September - December 2019, however, in their final test (post-test). test) reached 72.00\% of correct answers, similar percentages were presented by students aged between 23 to 25 years, where their percentage of correct answers in the pre-test was $30.50 \%$ and a significant increase of $75.36 \%$ in their test post-test. Not to mention the students with an age range over 25 years, where in their pre-test they presented $29.60 \%$ of correct answers and $75.25 \%$ in the post-test.

For the semester of January - April 2020, these students aged between 20 and 22 years old, presented a qualification of $28.50 \%$ in the pre-test and increased in the post-test a $74.50 \%$ of correct answers, being $51.85 \%$ the percentage that is traditionally maintained throughout this intervention.

What we do observe is the need to continue improving the quality of the content. However, with this experiment carried out, it can be reaffirmed that the use of Gamification is an excellent methodology for teaching the subject of Arithmetic and Geometry and another subject that can be integrated into the class program.

\section{Reference}

1. Alabbasi, D. (2018). Exploring Teachers 'perspectives towards using gamification techniques in online learning. Turkish Online Journal of Educational Technology, 17 (2), 35-45. https://doi.org/10.17718/tojde.328951

2. Armando, J. (2010). What we can learn from the video game on the teaching and educational materials. RELATEC, 9, (1), 29-42.

3. Castaño, C. (2009). Web 2.0. The use of the web in the knowledge society. University of Caracas. . Retrieved on $01 / 25 / 2021$

4. Cient, R., professional, f., \& Pedagog, d. and. 1. to. (2017). the technological revolution in the classroom through methodological symbiosis, 119-139.

5. Flores, E., \& Mariscal, J. (2010). Opportunities and challenges of mobile broadband in Latin America. Accelerating the digital revolution: broadband for Latin America and the Caribbean. Santiago de Chile: ECLAC. from http://telecomcide.org/docs/publicaciones/DTAP_267.pdf

6. Gamboa, M. A. (2016). Presentation "Appropriate uses of ICT in higher education". Reunion, 72, 59. Retrieved from.

7. Hernández, R., Fernández, C., \& Baptista, P. (2014). Investigation methodology. Mexico: McGrawHill.

8. Marcia Izabel Fugisawa Souza, S. F. (2011). Educational micro-content for mobile learning. Proceedings II International Congress of Digital Society, 2 (978-84-939077-5-4,), 1197-1206.

9. Olabe, M. J. (03 of 12 of 201 7). Computational thinking: bridging digital and educational gaps. Edmetic, 03. Retrieved on 02.09.2021

10. Salinas, J. (11 of 2004). Teaching innovation and use of ICT in university teaching. University and Knowledge Society Magazine, 01 (01). Retrieved 01/25/2021, from http://rusc.uoc.edu/rusc/es/index.php/rusc/article/download/v1n1-salinas/228-1150-2-PB.pdf

11. Sanjaya, R., Eva, A., Soekesi, M., Posmaria, A., \& Sitohang, S. (2015). Mobile Games Platforms for Teachers 'Entrepreneurship in Education. International Conference on Teaching and Learning, (December), 1-6. 